Vol. 1

No. 1

Jul - Dic 2016

ISSN: $2590-9215$ (En línea)

PP: $30-37$

\title{
La angustia, principio de posibilidad del conocimiento*
}

\author{
Anguish, Principle of possibility of knowledge
}

Aflição, princípio de possibilidade do conhecimento.

\author{
Carlos Fernando Álvarez-González ${ }^{* *}$
}

Forma de citar: Álvarez, C. F. (2016). La angustia, principio de posibilidad del conocimiento. Perspectivas. 1(1). $30-37$.

Recibido:

Diciembre 05 de 2015

Aceptado:

Marzo 02 de 2016

\section{Resumen}

El presente artículo de reflexión pretende examinar y desarrollar el concepto de la Angustia -principalmente en Kierkegaard- como principio de posibilidad en la producción de conocimiento. El filósofo a trabajar define la angustia como el temor venido de la nada. La aproximación a dicho concepto se realizó a partir del desarrollo de las categorías de falta, remordimiento, arrepentimiento, libertad y culpa. La investigación facilita comprender el momento de elección del individuo al conocer, lo que puede llevar a cambios estructurales en su representación acerca de cómo se aborda el papel de la misma en la producción del conocimiento desde la culpa.

Palabras Claves: Angustia, conocimiento, culpa, falta, libertad.

\begin{abstract}
The present reflection article tries to examine and develop the concept of the Anguish - mainly in Kierkegaard - as a principle of possibility in the production of knowledge. The philosopher to work defines the anguish as the fear that comes from nothing. The approach to this concept was made from the development of the categories of lack, remorse, repentance, freedom and guilt. Research facilitates to understand the moment of choice of the individual upon knowing, which can lead to structural changes in their representation about how the role of the same in the production of knowledge from guilt is addressed. Research makes it easier to understand the moment of choice of the individual when it is known, which can lead to structural changes in their representation about how the role of the same in the production of knowledge from guilt is addressed.
\end{abstract}

Key words: Anguish, knowledge, guilt, lack, freedom.

\section{Resumo}

Este artigo de reflexãotem por objetivo analisar e desenvolver o conceito da Aflição -principalmente em Kierkegaard - como princípio de possibilidade na produção de conhecimento. O filósofo define a aflição como o medo vindo do nada. A abordagem a este conceito foi baseado no desenvolvimento das categorias de fracasso, remorso,

*Esta investigación es producto de la asignatura Naturaleza Relacional del Ser Humano, de la Maestría en Asesoría Familiar y Gestión de Programas para la Familia. Universidad de la Sabana, Colombia.

${ }^{* *}$ Magíster en Bioética de la Universidad El Bosque (Colombia), Filósofo de la Universidad Industrial de Santander (Colombia). Profesor Universidad de la Sabana (Colombia). Correo electrónico: calphilo@yahoo.com.co 
arrependimento, liberdade e culpa. A pesquisa facilita a compreensão do momento de escolha do indivíduo ao conhecer, o que pode levar a mudanças estruturais na sua representação sobre cómo abordar o papel da mesma na produção do conhecimento da culpa.

Palavras chave: Aflição, fracasso, liberdade, remorso, conhecimento.

\section{Introducción}

Desarrollar un estudio de la Filosofía Existencial y aún más la de Soren Kierkegaard dentro de una mirada de Ciencia y Arte supone una tarea compleja y delicada, pues compromete abordar esta temática de la misma manera y con la misma rigurosidad como se lleva a cabo una investigación dentro del marco científico. En otro sentido, resulta también difícil ya que siendo el Ser Humano el objeto de estudio del Existencialismo, supone en sí mismo una indeterminación por la misma facultad que él posee, a saber, "la libertad de elegir". Ahora, el que una investigación dentro del marco del Existencialismo se aborde bajo la rigurosidad científica es una sugerencia del mismo filósofo danés.

Kierkegaard considera que el ser humano siempre se siente atraído por la falta, la carencia, llevándole a un sentimiento de desesperación. Para evitar esta desesperación, el individuo tiene que dar un "salto de fe" similar al de una vida religiosa. El individuo está llamado a este cambio debido al sentimiento de angustia que, en última instancia es un "temor a la nada".

El filósofo danés desarrolla el concepto de la Angustia en diversas obras, especialmente en el ensayo titulado El Concepto de la Angustia (1946), texto pensado a partir del mito del pecado original. Teniendo en cuenta la anterior idea, el autor realiza una lectura minuciosa del Génesis en la Biblia, evidenciando la angustia que experimentaron Adán y Eva durante su estancia en el paraíso, en especial cuando tienen que abandonarlo; momento en el que experimentan la libertad y en consecuencia la angustia. De modo que se podría deducir que todo hombre que experiencia la libertad vive en una angustia permanente. Ellos vivieron momentos angustiosos, y si bien tenían conciencia de que habían sido expulsados de allí, no sabían que les esperaba; y es precisamente este "no saber" y el hallarse en libertad lo que conlleva al individuo a sentirse angustiado. Dentro del trabajo Acerca de la angustia, Kierkegaard desarrolla también otros problemas subyacentes a ésta, entre los que cabe mencionar la falta, el remordimiento, la culpa, los cuales se trataran conceptualmente y de modo progresivo en la obra ya indicada.

El problema que aquí se desarrollará está basado en El Concepto de la Angustia (1946), obra en la que se ha identificado una idea principal y se pretenderá estudiarla. La idea en cuestión y que Kierkegaard tiene en mente es la consideración de la Angustia como un temor a la nada.

A partir de ahora, se pretenderá relacionar esta idea kierkegardiana con los siguientes interrogantes: ¿por qué el interés del hombre por el conocer? ¿Cuál es la causa por la que todos los seres humanos tienen intereses diferentes al momento de investigar? Los anteriores interrogantes se pueden responder tomando como punto de referencia el argumento de la racionalización de la 
Vol. 1

No. 1

Jul - Dic 2016

ISSN: $2590-9215$ (En línea)

PP: $30-37$ angustia, idea desarrollada por Kierkegaard en la obra mencionada. Para hacer posible esta relación, primero se debe comprender por qué Kierkegaard considera la Angustia venida de la nada como causa del pecado original, es decir, como causa de la caída del primer hombre. El desarrollo de esta noción conlleva a que se pregunte en un primer momento por el pecado original, seguido por la disertación de la nada en el contexto de la angustia y, por último, a la angustia como causa del pecado original.

Una vez comprendido estos cuestionamientos que se presentan en el hombre primigenio, se procederá, en un segundo momento a preguntarnos por el hombre posterior a Adán, intentando aclarar ¿qué sucede después de que el ser ha despertado de la ingenuidad? ¿Cómo actúa el hombre posterior una vez se hace y siente libre?

Un tercer momento se encargaría de focalizar la forma de cómo el hombre es capaz de afrontar el momento de crisis al que llega después de la primera caída. Dando un salto nuevamente para llegar al arrepentimiento introduciendo un nuevo concepto, el de la culpabilidad presente en el hombre posterior a Adán. Pues como se va a demostrar, se dice del hombre posterior que es culpable, en tanto que, de Adán se dice que es pecador. El culpable se siente como tal en tanto es consciente de la responsabilidad de sus actos. lo ha entendido mal eo ipso... si alguna ciencia pudiera explicarlo, todo sería confusión."(Kierkegaard, 1946, p.57), lo que supone que el primer pecado nace en el mismo hombre, surge de la prohibición de la que es sujeto, pues le está prohibido el quitarse la venda de los ojos y conocer, hacerse sabio. Cuando Dios le prohibió a Adán y Eva comer del árbol de la Ciencia del bien y del mal, parece ser que solo tuvo en cuenta su poder, más olvidó que había dotado a estos seres mortales de la capacidad de elegir, y el hecho de que un ser tenga la libertad de decidir lo hace indeterminado lo que no supone que se deje guiar siempre por el temor a un poder superior a éste, sino que, siempre se verá en la situación angustiosa de pensar en cuál sería su destino si opta por la segunda opción, es decir, si decide "desobedecer" y elegir su propio destino.

El asignar la responsabilidad de la primera caída del hombre a algo externo presupone un estado de inocencia, afirma nuestro filósofo "la inocencia es ignorancia. En la inocencia no está el hombre determinado como espíritu, sino psíquicamente, en unidad inmediata con su naturalidad" (Kierkegaard, 1946, p. 46), es decir, puesto que el espíritu del hombre se encuentra adormecido cualquier ser externo a él puede dominarlo. Si lo anterior es cierto se podría cuestionar la acción divina, pues cuando les hizo la mencionada prohibición olvidó el estado de estos personajes, la inocencia, la total ignorancia lo cual implica que no entendieron lo que Dios les prohibió no podían diferenciar el bien del mal. Asimismo, en este estado "la serpiente" no hubiese jugado un papel importante, pues al igual que Dios, ella jugó con las nociones de "Sabio", "Superior" las cuales eran desconocidas para ellos. Para poder dar una solución a estas cuestiones, Kierkegaard decide en primer lugar, eliminar del mito la "serpiente" como causa externa y como sujeto "tentador", en segundo, preparó un lugar propicio para la angustia en el ser humano, ese lugar se encuentra en el estado 
de la inocencia. Ahora bien, es claro que es el mismo hombre la causa de su primer pecado, pero, ¿qué es lo que causa en el hombre mismo la caída?

\subsection{La nada en el contexto de la angustia}

Una vez despejado el problema de la causa externa, se entra en el estudio acerca de lo que en el ser humano es la razón de su incertidumbre, aquello que le lleva a la desesperación. Entonces, ¿qué es lo que guía los actos humanos y que los conllevan a la desesperación? ¿Es el no conocer el destino lo que nos produce angustia?

Según lo planteado hasta el momento, es el hombre mismo quien decide su destino en el momento en el cual elije, del cual se deduce que, la angustia es un sentimiento causado por la no certeza de lo que sigue, es decir, cuando se elige por una opción siempre va a quedar en el pensamiento la posibilidad de qué hubiese sucedido si se hubiese escogido la otra posibilidad. Es en este momento cuando el autor logra llegar a una aproximación conceptual de lo que es la angustia "En este estado (es decir, el estado de inocencia) hay paz y reposo; pero hay al mismo tiempo otra cosa, que, sin embargo, no es ni guerra ni agitación - pues no hay nada con que guerrear. ¿Qué es ello? -Nada. Pero ¿qué efecto ejerce? -Nada. Engendra angustia. Soñando proyecta el espíritu de antemano su propia realidad; pero esta realidad es -nada; y la inocencia ve continuamente delante de sí esta nada." (Kierkegaard, 1946, p. 47). Por lo que sigue, la nada es en Kierkegaard la causa de la angustia, a su vez, es la angustia la que conlleva a la caída del primer hombre. Finalizando este primer apartado, en cuanto a la relación angustia- pecado original, se concluye que el profundo misterio de la inocencia consiste en que es a la vez angustia, imposibilitando conocer el estado de inocencia.

Lo anterior supone afirmar que la inocencia es al mismo tiempo angustia, refiriéndose así a la inocencia como un estado carente de algo, es de esta manera la inocencia aquello que mantiene dormido el espíritu. Cabe mencionar que fueron Adán y Eva los que despertaron el alma, al comer del fruto prohibido, transgresión que abrió la posibilidad del conocer y en consecuencia fue el comienzo de la Ciencia. De la búsqueda de la verdad, inquietud mediante la cual el hombre se pregunta por su mundo, por él mismo, por los demás, por su entorno, entre las múltiples preguntas que lo mantienen de cara al conocimiento.

Queda por verse, que posibilidad tendría el hombre de adquirir o llegar a un conocimiento sin límites. Ya que la angustia como realidad de la libertad y según el autor es la posibilidad antes de la posibilidad. También, cabría preguntarse hasta donde llegan los límites de la ciencia, pues aun cuando el hombre se encontraba en el estado de inocencia, su libertad no conocía ningún límite, ahora que ha despertado de su inocencia, ¿sigue siendo su libertad ilimitada? $\mathrm{O}$ ¿se encuentra atada al libre arbitrio?

\subsection{De la ingenuidad a la posibilidad del conocimiento}

El anterior apartado sustentó la acepción de la angustia como un sentimiento causado por la no certeza de lo que sigue, en este se llegó a diversos interrogantes, los cuales se presentan en el hombre primigenio. Ya sustentada esta idea es necesario, siguiendo los planteamientos del autor, preguntarse 
un camino para no sentir angustia, pero ¿de qué? No se sabe de qué se tiene angustia, pero permite entender el autor que el hombre siente angustia ante el ilimitado número de preguntas y dudas que surgen en su pensamiento sobre el mundo y acerca de sí mismo, esto es precisamente lo que le angustia. Por ahora lo que se pretende desarrollar es una inquietud acerca del interés del hombre por conocer, el cuál puede expresarse así: ¿por qué el interés del hombre por el conocer? ¿Qué hace que algunos hombres tengan intereses particulares para conocer? Esto se puede responder, mediante el análisis que hace Kierkegaard en cuanto a la racionalización de la angustia. Pero antes de pasar a este punto es menester aclarar algunos aspectos acerca de la noción que ya se ha explicitado en el apartado anterior: la Angustia.

Pues bien, la angustia siempre ha estado en el hombre (Kierkegaard, 1946, p. 64) es lo que enseña Kierkegaard, y como se ha anotado que la angustia genera conocimiento, el hombre constantemente se encuentra en potencia de conocer el mundo, dado que vive en estado de angustia. Esta afirmación permite definir la angustia de dos formas: de una parte, como el despertar del adormecimiento en el que se encontraba el espíritu, y de otra, como aquel sentir que está permanente en el hombre. Como es bien sabido, el hombre aún no conoce la totalidad de la naturaleza, por lo tanto, es ésta quien aviva el espíritu científico, ya que el hombre de ciencia al sentirse ingenuo ante el mundo, siente miedo, lo que lo lleva a angustiarse y salir de ese estado intentando discernir acerca de las leyes de la naturaleza.

Puede en este momento acudirse a un ejemplo: para formular una ley el hombre de ciencia realiza el siguiente proceso. En un primer momento, el hombre observa a su alrededor y reproduce las observaciones referidas a un proceso natural con la ayuda de una tabla, que muestra magnitudes variables que caracterizan el proceso. El segundo paso es descubrir una función (simbolizada mediante una fórmula) que representará la distribución de valores que existen en la tabla, es decir, abrirá la posibilidad de condiciones para los diferentes modelos de los cuales se pretenda hacer partícipe. Introducir una fórmula equivale a introducir aquella Ley que describe los procesos observados. Aún más, esta contiene más de lo que es observado actualmente, pues debe regir para procesos de tipo similar. Para una descripción de la naturaleza las leyes abstractas -fórmulas- deben correlacionarse con el ámbito de realidad al que pueden aplicarse. En este momento el científico saca unas proposiciones generales que serán los axiomas en los cuales va a basar su teoría, para luego exponer ciertas proposiciones que servirán como aquellas leyes que expliquen la naturaleza del Universo (Schlick, 2002, p.33 ss).

Una vez el hombre de ciencia postula una ley -representada en una fórmula-, se da cuenta que la naturaleza es aún más compleja que la fórmula y vuelve a sentirse ignorante ante la complejidad del Universo lo que lo lleva a sentir nuevamente angustia. En este momento el hombre comienza nuevamente a observar la naturaleza, a plantear hipótesis, vuelve a repetir el proceso por el cual la ciencia postula las leyes físicas que se acomodan a la dinámica del cosmos. De esta manera se puede observar cómo la angustia presente en el individuo posterior a Adán ha servido como aquella fuerza que impulsa al hombre a preguntarse y en consecuencia a inquietarse por conocer dicho ámbito.

Por otro lado, Kierkegaard ha dicho que el hombre entre más original sea, es más carente de espíritu (inocente) y que el hombre noprimordial, es más espíritu (racionaliza y conoce la angustia) y no es inocente, pero ¿Qué significa racionalizar y conocer la angustia? Significa que el hombre, aunque no sabe qué lo angustia tiene la capacidad de actuar en procura de bajar de intensidad la 
angustia que siente. Volvamos a un ejemplo: a un hombre que lo angustie el mundo, puede racionalizar esa angustia, es decir, calmar su angustia, cuestionándose, preguntándose e investigando por la procedencia de éste, o sea por el origen del Universo. El que se afirme que el mundo angustia, no implica que se tenga pleno conocimiento del objeto de la angustia, lo que sucede es que el hombre al preguntarse por el mundo, le surgirán un sinnúmero de preguntas que lo van a llevar a angustiarse, ¿Por qué? porque tendrá tantas inquietudes que no será capaz de correlacionarlas, lo que lo llevará a sentirse en un estado anormal. Es aquí cuando el "hombre posterior" racionaliza su angustia y decide tomar sólo aquellos cuestionamientos que tengan alguna correlación y seleccionar un ámbito en el cual se va a dedicar a investigar, bajando de esta manera los niveles de ansiedad que le producen angustia.

Hasta ahora, la idea expuesta en este apartado permite resaltar la importancia de la angustia como aquel sentimiento que, aunque se encuentra presente en todos los seres humanos, aun cuando cada uno lo siente de manera totalmente distinta, (Kierkegaard, 1946, pp. 83-84) lo que da a entender por qué los hombres percibimos el mundo de diferente manera y por qué la ciencia tiene tantas y diversas tesis propuestas. De modo que el hombre se inquieta de acuerdo a aquello por lo cual siente angustia, además de cómo siente la angustia, como la padece. Sus preguntas por saber y por conocer están precedidas del sentimiento de la angustia, el mismo del cual no se puede liberar y que se acrecienta de manera proporcional al aumento de la angustia.

Para poder diferenciar porque algunos seres se interesan por diversos ámbitos del saber, es necesario introducir dos nociones propias del autor pertinentes para el caso, a saber, el salto cualitativo y el salto cuantitativo; el primero alude a aquello propio del individuo, en tanto, que el segundo hace referencia a aquello que corresponde a la especie. (Kierkegaard, 1946, p. 61). El momento en que el hombre se encuentra en "crisis", da un salto cualitativo y cuantitativo, o sea, en la medida en que el hombre se angustia da un salto cuantitativo, ya que es propio de la especie angustiarse, y da un salto cualitativo en la manera como sienta esa angustia que lo agobia. En la proporción en que se despierte la crisis se prepara el individuo para afrontar -racionalizar- la postcrisis $^{2}$, una afirmación como ésta conduce a un nuevo interrogante ¿cómo va a reaccionar ante la angustia presente?

\section{Acerca de la culpa en Kierkegaard}

A propósito de la Angustia, en tanto que posibilidad, la última parte de esta meditación intenta abordar la idea de posibilidad en Kierkegaard. Teniendo en cuenta la postura del autor en su disertación del capítulo III de la obra propuesta como base, para esta intervención se acerca aún más a la clarificación del concepto de la angustia, esta vez desde la categoría de la culpa.

En esta última parte se focaliza el interés, por la forma cómo el hombre es capaz de afrontar este momento de crisis - en este apartado se le llamará de otro modo a esta crisis, introduciendo la categoría de culpa-, dando un salto al arrepentimiento: "tan pronto como está puesta la culpa, ha pasado la angustia y existe el arrepentimiento" (Kierkegaard, 1946, p. 116). Es precisamente por lo anterior que en este caso se irá a hablar de la culpa

"Se denomina "crisis" al "cambio brusco en el curso de una enfermedad, ya sea para mejorarse, ya para agravarse el paciente". En nuestro caso serían aquellos momentos donde la persona presente sintomatología angustiosa.

${ }^{2}$ En su obra sobre el concepto de la angustia Kierkegaard avizora a la angustia como una enfermedad psicológica, por lo tanto, aquí es tratada como tal. Kierkegaard, S. (1946). El Concepto de la Angustia. Buenos Aires: Espasa-Calpe. P. 47. 
Adán como el pecador, refiere a una consideración que en palabras del pensador se da por el salto cuantitativo, es decir, por la generación histórica. La razón de la anterior situación se debe, por un lado, a que el primer hombre carecía del lenguaje, y por la otra, que la síntesis de alma, cuerpo y espíritu no es como la del hombre posterior, esto es, que la síntesis del hombre posterior se encuentra más sustentada que la de Adán, por lo tanto, la angustia aumenta en el hombre posterior. Esta angustia se ve representada en la culpabilidad. Como se había anunciado, Adán es el hombre pecador - recuérdese que es por el salto cualitativo- diferente del hombre posterior que al tener conciencia se vuelve un hombre culpable. Ahora bien, ¿cómo es que Kierkegaard llega a establecer la relación de la culpa y la angustia? ¿Dónde deja entrever a la culpa como la angustia del hombre moderno?

El filósofo danés en su obra, expone a la angustia relacionada abiertamente con la culpa, de lo cual se podría sacar algún provecho ¿Cómo?, proponiendo que se llega a la verdadera perfección mediante la culpa. Kierkegaard lo sustenta de la siguiente manera: "No obstante, presenta la vida bastantes fenómenos en los cuales el individuo, presa de la angustia, persigue casi concupiscentemente la culpa $\mathrm{y}$, sin embargo, la teme. La culpa tiene sobre los ojos del espíritu el poder que se dice ejerce la mirada de la serpiente: fascina" (Kierkegaard, 1946, p.117). Esta parálisis es la que precisamente colabora para el salto que necesita el individuo para pasar de la culpa al arrepentimiento, lo cual es la causa de la perfección. En otras palabras, la culpa es un sentimiento que "juega" con la conciencia del hombre, pues constantemente le está empujando al arrepentimiento y luego vuelve y lo embarga para hacerlo nuevamente culpable.

Es en este ir y venir, donde el individuo se encuentra consigo mismo, donde descubre en la culpa esa compañera que le servirá de base para su encuentro con la libertad, "lo primero que hace es volverse a sí mismo. Y recibe por continua compañera a la culpa, como el genio inmediato al destino" (Kierkegaard, 1946, p.121). Vemos pues, como Kierkegaard en esta aborda la categoría del genio. El genio es una noción especial para el autor, pues se relaciona con la angustia dado a que es el genio "el que reflexiona de manera activa y aplicada sobre las situaciones del mundo".

En definitiva, el genio vive en aras del futuro, en aras de la angustia, es decir, que el genio al tomar posesión de sí mismo descubre la culpa. Se hace consciente y prueba que la culpa es esencial en su sensibilidad, descubriendo que su libertad depende en gran medida de su relación con la culpa, la libertad del hombre -si éste se acoge a la categoría ahora considerada, la de genio- se encuentra en la subjetividad de cada ser al igual que la culpa.

A modo de conclusión, podría decirse que la angustia es la generadora de la culpa, puesto que las dos están, como hemos visto, en una relación estrecha con la libertad, sabiendo que la libertad es fundamental para la angustia, puesto que: "la relación de la libertad con la culpa es de angustia, porque la libertad y la culpa son todavía una posibilidad" (Kierkegaard, 1946, p.123). Por lo tanto, cuando la libertad se encuentra en una persecución de sí misma con "un deseo apasionado", deseando alejarse de la culpa, no puede liberarse de ella por la misma insistencia de la angustia que embarga constantemente en el hombre.

Queriendo establecer un cierre oportuno a la temática planteada podría definirse la culpa como aquello que hace posible el sentimiento, este sentimiento es lo que antes nos angustiaba. La culpa es interna, subjetiva, por eso se puede correlacionar con la angustia, todos los individuos se encuentran dentro de la posibilidad de sentirse culpables. Aun cuando cada individuo experiencia esta angustia o culpabilidad de un modo totalmente diferente, mejor aún, la culpa como categoría subjetiva 
e interna es carente de toda diferenciación. Y no solo es carente de diferenciación porque sean iguales en todos los hombres, sino porque no se pueden establecer diferencias ni decir quién es más culpable, tan sólo se puede enunciar quien se siente culpable, cada uno en su interior formará sus jerarquías en cuanto a qué le hace sentir más culpable y qué le hace sentir menos culpable.

\section{Bibliografía}

\section{Bibliografía Primaria}

Kierkegaard, Søren. (1946). El Concepto de la Angustia. Buenos Aires: Espasa-Calpe.

Chestov, León. (1965) "Kierkegaard y la filosofia existencial”. Traducción Ferrater Mora. Cap. VII. Buenos Aires Sudamericana.

Schlick, Moritz. (2002). Filosofía de la Naturaleza. Traducción y notas, José Luís González Recio. Madrid: Encuentro S.A.

\section{Bibliografía Secundaria}

Kierkegaard, Søren. (1962). Diario de un seductor. Tomo I. Brescia: Morcelliana,

Castorina, José. (2003). Representaciones

Sociales: Problemas teóricos y conocimientos infantiles. Barcelona:

GEDISA, S.A. 